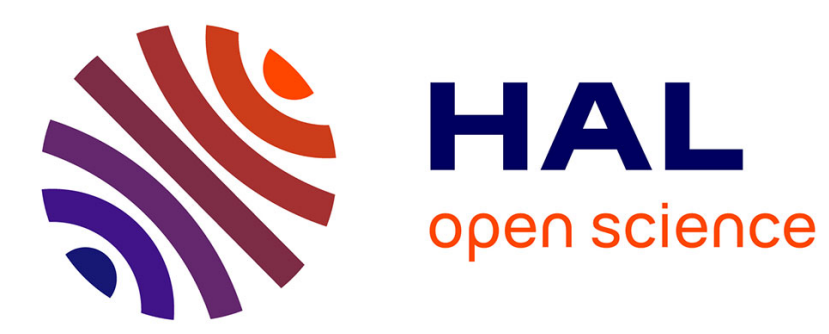

\title{
The paths between gender, barriers, social support, coping efficacy and vocational indecision
}

\author{
Isabelle Fort, Anca Murariu
}

\section{To cite this version:}

Isabelle Fort, Anca Murariu. The paths between gender, barriers, social support, coping efficacy and vocational indecision. International Journal for Educational and Vocational Guidance, 2018, 10.1007/s10775-018-9359-4 . hal-01791439

\section{HAL Id: hal-01791439 \\ https://hal-amu.archives-ouvertes.fr/hal-01791439}

Submitted on 16 May 2018

HAL is a multi-disciplinary open access archive for the deposit and dissemination of scientific research documents, whether they are published or not. The documents may come from teaching and research institutions in France or abroad, or from public or private research centers.
L'archive ouverte pluridisciplinaire HAL, est destinée au dépôt et à la diffusion de documents scientifiques de niveau recherche, publiés ou non, émanant des établissements d'enseignement et de recherche français ou étrangers, des laboratoires publics ou privés. 
The Paths Between Gender, Barriers, Social Support, Coping Efficacy and Vocational Indecision

Isabelle Fort \& Anca Murariu 


\begin{abstract}
We investigated the paths between gender, social support, barriers, coping efficacy, and vocational indecision, in the light of social cognitive career theory. A path model was tested with a sample of 203 undergraduates. We expected coping efficacy to partially mediate the paths between career barriers, educational barriers, social support and indecision. However, this prediction was only confirmed for educational barriers. Results are discussed with reference to the literature and in terms of their practical implications.
\end{abstract}

Keywords: social support, barriers, self-efficacy for coping with barriers, gender, vocational indecision

\title{
Résumé
}

Cette étude porte sur les relations entre sexe, soutien social, obstacles, auto-efficacité à faire face aux obstacles et indécision vocationnelle, à la lumière de la théorie socio-cognitive de l'orientation. Un modèle en pistes a été mis à l'épreuve à partir d'un échantillon de 203 étudiants. Un effet médiateur partiel de l'auto-efficacité à faire face aux obstacles dans la relation entre obstacles liés à la carrière, obstacles liés aux études, soutien social et indécision était attendu. Cependant, cet effet a été observé seulement pour les obstacles liés aux études. Les résultats observés sont discutés en référence à la littérature et en termes d'implications pratiques.

Mots clés: soutien social, obstacles, auto-efficacité à faire face aux obstacles, sexe, indécision vocationnelle 


\section{The Paths Between Gender, Barriers, Social Support, Coping Efficacy and Vocational Indecision}

Vocational indecision is defined as "the inability to make a decision about the vocation one wishes to pursue" (Guay, Senécal, Gauthier, \& Fernet, 2003, p. 165). Yet the ability to make a decision is important in vocational development since behaviors related to decision-making skills are part of adaptive career behaviors mentioned by Lent and Brown (2013) in their model of career self-management across the lifespan. Moreover, negative consequences of indecision were empirically proven. A high level of vocational indecision can entail a lack of person-occupation fit, a decrease in career motivation and in well-being (Feldman, 2003). These results highlight the need to identify antecedents of vocational indecision.

\section{Social Cognitive Career Theory}

One model, originating from Social Cognitive Career Theory (SCCT, Lent, Brown, \& Hackett, 1994), was elaborated to describe antecedents of indecision. It is the career selfmanagement model, as applied to career exploration and decision-making behavior (Lent \& Brown, 2013). In this model, career decision self-efficacy determines outcomes (level of decidedness, indecision or decisional anxiety) directly and indirectly through outcome expectations, goals and actions. Indeed, Lent and Brown (2013) supposed that career decision self-efficacy is positively related to outcomes in so far as individuals with more confidence at engaging in decisional behaviors are more likely to make a decision. Moreover, outcomes (level of decidedness, indecision or decisional anxiety) are also influenced by contextual variables (social support and barriers). Individuals who perceive more barriers have more difficulties to make a decision and individuals who perceive more social support are more able to make a decision. 
This model was partially investigated by Lent et al (2016). In this study, authors examined relationships between self-efficacy, social support, decisional anxiety and decidedness, using structural analyses. Their results highlight significant paths between selfefficacy and outcomes (decisional anxiety and decidedness). Significant negative paths between career decision self-efficacy, career search self-efficacy and another measure of outcomes, indecision, were also observed by Betz and Voyten (1997), Creed et al. (2006) and Nota et al (2007).

Other authors investigated relationships between contextual variables (barriers and social support) and indecision. According to the career self-management model, as applied to career exploration and decision-making behavior, individuals who perceive more barriers have more difficulties to make a decision. However, results on these paths were less consistent. Constantine et al. (2005) observed a significant positive path between barriers and indecision, but Lopez and Ann-Yi (2006) reported varying results according to group (White, African American, or Hispanic) and type of barrier (educational or career-related). Only educational barriers were significantly related to indecision in White participants whereas in African American participants and in Hispanic participants, this path was significant for educational and career barriers. Their results highlight the relevance of distinguishing between educational and career barriers.

The model also postulates that those who perceive more social support are more able to make a decision. Nota et al. (2007) found that the path between social support and indecision was significant and negative for family support, whereas Lopez and Ann-Yi (2006) found that it was nonsignificant. In a similar vein, Lent et al (2016) observed nonsignificant paths between social support and decisional anxiety and between social support and decidedness (whereas correlations are significant). These divergences can partially be explained by statistical reasons. In their study, Lopez and Ann-Yi (2006) performed 
regressions with social support, barriers and barrier coping efficacy as predictors.

Multicollinearity can explain the nonsignificant path between social support and indecision. Lent et al (2016) observed significant correlations between social support, decidedness and decisional anxiety, but in structural analyses including other variables, this path was no more significant. These divergent results highlight the need to integrate the paths in more comprehensive models.

Hypothesis 1: we expect to find significant positive paths between barriers and indecision.

Hypothesis 2: we expect to find significant negative paths between social support and indecision.

\section{Role of Coping Efficacy}

The career self-management model, as applied to career exploration and decisionmaking behavior, is focused on career decision self-efficacy, but Lent and Brown (2013, p. 562) specified that "process efficacy and coping efficacy are central forms of self-efficacy in our self-management model". The importance of coping efficacy has been stressed by several authors (Lent, Brown, \& Hackett, 2000; Raque-Bogdan, Klingaman, Martin, \& Lucas, 2013). According to Byars-Winston and Fouad (Byars-Winston \& Fouad, 2008, p. 427), “coping efficacy affects emotional reactions as well as behavior, especially related to anxiety and stress reactions to unfamiliar or potentially aversive situations", and we can certainly regard decisional behaviors as potentially aversive situations. Thus, we can suppose that anxiety and stress make difficult the process of decision making and so, that coping efficacy is related to indecision. To our knowledge, the paths between different dimensions of coping efficacy and career indecision have only previously been investigated in a study of women from three ethnic groups (Lopez \& Ann-Yi, 2006). These paths were significant and negative in some instances, but not in others. Lopez and Ann-Yi (2006) concluded that some barriers are more 
salient in some groups than in others, and subsume much of the variance associated with selfefficacy.

Moreover, several authors have suggested that contextual variables promote coping efficacy. More precisely, individuals with a high level of social support are supposed to have strong beliefs in their ability to overcome barriers and individuals who expect more barriers are supposed to have weaker beliefs in their ability to overcome barriers. Results relative to the path between social support and coping efficacy corroborated this hypothesis. Significant positive paths between social support and coping efficacy were observed in empirical studies (Lopez \& Ann-Yi, 2006; Raque-Bogdan et al., 2013). The paths between barriers and coping efficacy have also been investigated. Lopez and Ann-Yi (2006) observed significant negative paths between educational barriers and self-efficacy for coping with these barriers. Results for the path between career barriers and career barriers coping efficacy were, however, less consistent. This path was found to be significant and negative in some previous studies (Byars-Winston \& Fouad, 2008; Perrone, Civiletto, Webb, \& Fitch, 2004; Tate et al., 2015), but nonsignificant in one (Lopez and Ann-Yi, 2006) that looked at different ethnic groups (white and African American). The divergence observed by Lopez and Ann-Yi (2006) can be explained by differences in sample sizes. This correlation is not significant in smaller samples. It also underscores the relevance of investigating these paths for both educational barriers and career barriers. Thus, as in the validation studies of the career choice model, it might well be worth investigating the role of coping efficacy in the career self-management model applied to career exploration and decision-making behavior.

Hypothesis 3: we expect to observe significant negative paths between educational barriers and educational barriers coping efficacy, and between career barriers and career barriers coping efficacy. 
Hypothesis 4: we expect to observe significant positive paths between social support and coping efficacy.

Hypothesis 5: we expect to observe significant negative paths between coping efficacy and indecision.

Contextual variables were supposed to be related to coping efficacy and coping efficacy was supposed to be related to indecision. So, we can consider that coping efficacy mediates the path between contextual variables and indecision. When Lent et al. (2016) investigated the paths between social support, self-efficacy, decisional anxiety and decidedness in a structural model, they found that self-efficacy (including career decision selfefficacy and coping efficacy) mediated the paths between social support, decisional anxiety and decidedness. The results reported by Lopez and Ann-Yi (2006) provided clues to the role that coping efficacy may play in the mediation between barriers and indecision. As regards educational barriers, when these authors introduced educational barriers coping efficacy into the regression, the effect of educational barriers ceased to be significant for their African American participants and for their Hispanic participants. By contrast, it remained significant for white participants. Although mediation tests were not performed, results appeared to corroborate the mediation hypothesis for educational barriers, depending on the group. Concerning career barriers, their results corroborated the partial mediation hypothesis only for Hispanic participants, but the introduction of career barriers coping efficacy failed to change the path between career barriers and indecision for white and African American participants.

Hypothesis 6: The path between social support and indecision is mediated by coping efficacy.

Hypothesis 7: The path between barriers and indecision is mediated by coping efficacy.

\section{Personal Factors}


In previous models of SCCT, Lent, Brown, and Hackett (Lent et al., 1994) highlighted the need to consider personal factors such as gender and ethnicity. These are important variables in career development, because they can elicit reactions from the social environment. They are present in another model from the SCCT, the career choice model (Lent, 2005) and are assumed to be related to contextual influences (social support and perceived barriers). Some of these paths have been empirically confirmed (Cardoso \& Marques, 2008; Lindley, 2005; Luzzo \& McWhirter, 2001; Raque-Bogdan et al., 2013; Watts, Frame, Moffett, Van Hein, \& Hein, 2015). Women apparently expected to encounter more career-related barriers than men, but receive more emotional support than them. However, scores for educational barriers did not vary according to gender. As gender was related to social support and barriers, which are both assigned an important role in the model of career self-management applied to career exploration and decision-making behavior, we felt it would be relevant to include this variable in the model we tested in the current study.

Hypothesis 8: we expected gender to be related to social support, as it is in the career choice model.

Hypothesis 9: we expected gender to be related to perceived barriers, as it is in the career choice model.

\section{Purpose of the Study}

To summarize, the aim of the present study was to investigate the paths between gender, social support, perceived barriers, coping efficacy and vocational indecision. The predicted paths are displayed in Figure 1. The results would enable us to highlight the role of gender, as well as the specific role of coping efficacy in an adaptation of the model of career self-management applied to career exploration and decision-making behavior. They would also allow us to examine whether paths differ according to type of barrier. As such, they would inform the design of interventions based on the variables in our model (coping efficacy 
in particular), and indicate whether this type of intervention would be most relevant for men or for women.

Insert Figure 1 about here

\section{Method}

\section{Participants and Procedure}

Participants were 154 undergraduates (37 men, 117 women) in their third year of law, management, art history, literature, the arts or psychology at a university in Provence (South of France). Their ages ranged from 19 to 23 years $(M=21.6, S D=0.84)$. We chose third-year students because this meant they were nearing the end of their degree course and were having to decide whether to continue studying either the same or a different discipline, or look for a job. Researchers recruited them before classes. Participants were invited to take part in a study concerning vocational activities on a voluntary basis. They were advised that their responses would be anonymous and would be used for research purposes only. Those who agreed were given questionnaires to complete and completed them in the classroom.

\section{Measures}

We developed French adaptations of all the scales used in this study. Selected scales were translated by two English-speaking experts in vocational issues, after which translators determined which translation best represented the meaning of the original item. In the event of a disagreement, we found a translation that satisfied both translators. The translated scales were then administered to a small sample of participants to make sure that the items were clearly understood. Items were then modified following suggestions of participants.

\section{Perception of barriers.}

The Perception of Barriers Scale (POB; Luzzo \& McWhirter, 2001) contains two subscales: Career-related barriers (11 items) and Educational barriers (21 items). Items ask participants if they think they may experience these barriers in their future lives (e.g., lack of 
support from teachers). Participants answer on a 5-point Likert scale ranging from strongly disagree to strongly agree. This scale has proven homogeneity and stability (Luzzo \& McWhirter, 2001). The homogeneity of the original scale, as measured by Cronbach's alpha, was .86 for Career barriers and .88 for Educational barriers, while test-retest reliability over a 2-month period was also satisfactory $(r=.72$ for Career barriers, $r=.68$ for Educational barriers). When Lipshits-Braziler and Tatar (2012) performed a principal component analysis on the Career barriers subscale, three factors emerged: ethnic discrimination, gender discrimination, and childcare and family issues. When we verified the structure of our French version of this scale by confirmatory factor analysis (CFA), we obtained a two-factor model, with one factor including educational barriers and the other career barriers. Moreover, in this second factor, we identified three subfactors: ethnic discrimination, gender discrimination, and childcare and family issues. This model provided an adequate fit to the data $\left(\chi^{2}=330.69\right.$ $(d f=240)$, comparative fit index $(\mathrm{CFI})=.90$, root mean square error of approximation $($ RMSEA $)=.05)$. All items significantly loaded onto the expected factor. Loadings varied between .53 and .95 for career barriers, and between .28 and .66 for educational barriers. We then estimated the internal consistency of the French version of this scale, as done for the original scale. Internal consistency of the subscales, as measured by Cronbach's alpha, was .71 for Career barriers and .80 for Educational barriers. For each subscale, a high score corresponded to the perception of more barriers.

\section{Coping with barriers.}

The Coping With Barriers Scale (CWB; Luzzo \& McWhirter, 2001) was developed to mirror the POB, so it contains two subscales (Coping with career barriers and Coping with educational barriers). Participants have to indicate their degree of confidence that they can overcome each potential barrier on a 5-point scale ranging from not at all confident to highly confident (e.g. lack of financial support). It has proven reliability and stability (Luzzo \& 
McWhirter, 2001). Cronbach's alphas for the original scale were .88 for Coping with careerrelated barriers and .93 for Coping with educational barriers. Test-retest reliability over a 2month period indicated moderate stability $(r=.50$ for Coping with career related barriers, $r=$ .49 for Coping with educational barriers). As with the Career barriers subscale, LipshitsBraziler and Tatar (2012) performed a principal component analysis on the Career barriers coping subscale, which revealed three factors: ethnic discrimination, gender discrimination, and childcare and family issues. We performed a CFA on the French version of the scale. Results yielded a bi-factorial model, with one factor including educational barriers coping and the other career barriers coping. Moreover, in this second factor, we identified three subfactors: ethnic discrimination, gender discrimination, and childcare and family issues. This model provided an adequate fit to the data $\left(\chi^{2}=379.0(d f=243)\right.$, CFI $=.90$, RMSEA $\left.=.06\right)$. All items significantly loaded onto the expected factor. Loadings varied between .51 and .79 for career barriers and between .42 and .67 for educational barriers. The internal consistency of the French version, as measured by Cronbach's alpha, was .78 for Career barriers coping efficacy and .88 for Educational barriers coping efficacy. A high score corresponded to a high level of coping efficacy.

\section{Career indecision.}

We used the indecision items from the Career Decision Scale (CDS; Osipow, 1987). This scale consists of two subscales (Certainty of career choice and Indecision). The Indecision subscale contains 16 items (e.g., "I don’t know what my interests are”). Responses are recorded on a 4-point scale ranging from like me to not like me. The psychometric qualities of this scale have been highlighted in several studies. Hartman, Fuqua, and Hartman (1983) reported a satisfactory estimate of internal consistency $(\alpha=.83)$. The scale's concurrent validity, construct validity and predictive validity have also been documented (Hartman et al., 1983; Hartman \& Hartman, 1982). Hartman, Fuqua, and Hartman (1983) 
observed significant paths between scores on the CDS and variables related to indecision (identity, anxiety, and locus of control). Hartman and Hartman (1982), meanwhile, showed that the CDS score significantly predicts indecision one year after graduation. However, results on the structure of this scale are inconsistent. Stead and Watson (1993) found that all the items of the CDS loaded onto the same factor, Hartman, Fuqua, and Hartman (1983) obtained two-factor structure, and Hartman and Hartman (1982) obtained a three-factor one (these factors could be interpreted as difficulty taking a decision, lack of knowledge about oneself, and inability to follow one's favorite choice because of external barriers). We then performed a CFA to see whether our French version of this scale could be hierarchically structured. We highlighted the same three factors as Hartman and Hartman (1982), except that these were influenced by a more general factor. This model provided an adequate fit to the data $\left(\chi^{2}=168.40(d f=92), \mathrm{CFI}=.92, \mathrm{RMSEA}=.07\right)$. All items significantly loaded onto the expected factor. Loadings varied between .24 and .87 . The internal consistency of the French version of the global scale, as measured by Cronbach's alpha, was .88. A high score corresponded to a high level of indecision.

\section{Social support.}

We opted for the Multidimensional Scale of Perceived Social Support (MSPSS, Zimet, Dahlem, Zimet, \& Farley, 1988). This scale measures social support from different sources, including family members, friends and other persons. The original version contains 12 items, which respondents rate on a 7-point scale ranging from very strongly disagree to very strongly agree (e.g., "I can talk about my problems with my friends"). The psychometric qualities of this scale have been described elsewhere (Zimet et al., 1988). Zimet et al. (1988) highlighted the scale's satisfactory internal consistency $(\alpha=.88)$ and high test-retest reliability $(r=.85$ for a 2- to 3-month interval). They also found a three-factor structure comprising significant other, family and friends. These factors were correlated (Zimet et al., 1988). Osman et al. 
(2014) highlighted the scale's structural model invariance across women and men. A CFA performed on the French version yielded a hierarchical model, with the same factors as those observed in the original version (significant other, family and friends), plus a more general factor. This model provided an adequate fit to the data $\left(\chi^{2}=46.63(d f=26), \mathrm{CFI}=.98\right.$, RMSEA $=.07)$. All items significantly loaded onto the expected factor. Loadings varied between .71 and .96 . The internal consistency of the French version, as measured by Cronbach's alpha, was .92. A high score meant more social support.

\section{Data analysis}

We first performed a CFA to test a measurement model and then we conducted path analyses using AMOS 16.0 to test our hypothetical model. Owing to the small sample size, we had to reduce the number of indicators. We therefore focused on the factors or subfactors yielded by the CFA we performed on every scale and choose factors or subfactors in line with our hypotheses. So, we computed aggregate scores as measures of the following variables: career barriers, educational barriers, career barriers coping efficacy, educational barriers coping efficacy, indecision, social support, and we performed a further CFA. Path analyses were performed on sample covariances, and we used maximum likelihood as our method of estimation. We used listwise deletion to deal with missing data, and gender was modeled as an ordinal variable. We report several fit indices: $\chi^{2} / \mathrm{df}$-ratio, RMSEA and CFI. For the CFI, values above .95 represent a good fit and values above .90 an adequate one. For the RMSEA, values below .06 represent a good fit and values below .10 an adequate one (Hu \& Bentler, 1999).

\section{Results}

Descriptive statistics and a correlation matrix are displayed in Table 1. We found significant correlations between indecision and both types of barriers, indecision and both dimensions of coping efficacy, indecision and social support, both dimensions of barriers and 
both dimensions of coping efficacy, educational barriers and social support, and educational barriers coping efficacy and social support.

\section{Insert Table 1 about here}

We began by testing a measurement model. The measurement model provided an adequate fit with the observed data $\left(\chi^{2}=118.10(d f=64), \mathrm{CFI}=.94, \mathrm{RMSEA}=.07\right)$. All loadings were significant. They varied between .43 and .87 .

We then tested our hypothetical model. As career barriers, educational barriers, career barriers coping efficacy and educational barriers coping efficacy were correlated dimensions of the same scales, we allowed error variances of the barriers and coping dimensions to correlate. We also allowed errors associated with social support and educational barriers to correlate. The first model we tested corresponded to our hypothetical model, and was a good fit with the data $\left(\chi^{2}=6.7(d f=6), \mathrm{CFI}=.99\right.$, RMSEA $\left.=.03\right)$. However, the paths between gender and educational barriers, social support and career barriers coping efficacy, educational barriers and indecision, career barriers coping efficacy and indecision, career barriers and indecision, social support and indecision were all nonsignificant. Hypothesis 1 was not confirmed. The path between barrier and indecision was not significant whatever the type of barrier. Social support was not significantly related to indecision, contrary to was expected in hypothesis 2 . Hypothesis 3 was confirmed. We observed significant negative paths between barriers and barriers coping efficacy, regardless of the type of barrier. Partially in accordance with hypothesis 4 , significant positive paths between social support and educational barriers coping efficacy were observed. Hypothesis 5 was also partially confirmed, as the path between coping efficacy and indecision was significant, but only for educational barriers coping efficacy. In line with Hypotheses 8 and 9, gender was related to contextual variables, career barriers and social support. Women expected to encounter more 
career barriers but received more social support than men. By contrast, the path between gender and educational barriers was not significant.

The indirect effects were tested with 1000 bootstrap samples to test hypotheses 6 and 7. These effects were significant for the paths between educational barriers and indecision $(\beta$ $=.12, S E=.15,95 \% \mathrm{CI}[.02, .40])$, but were nonsignificant for the paths between career barriers and indecision $(\beta=.13, S E=.10,95 \% \mathrm{CI}[-.17, .02])$, and between social support and indecision $(\beta=-.12, S E=.09,95 \%$ CI $[-.12, .01])$. Hypothesis 7 was only confirmed for educational barriers and hypothesis 6 was not confirmed. Educational barriers coping efficacy mediated the path between educational barriers and vocational indecision. No such mediation was observed either for career barriers or for social support. This final model is displayed in Figure 1.

Insert Figure 1 about here

\section{Discussion}

The aim of the present study was to investigate the paths between gender, barriers, social support, coping efficacy and vocational indecision. To this end, we administered four scales to a sample of students, and used path analyses to test our model.

Our results confirmed the relevance of distinguishing between career and educational barriers, in so far as results varied according to the type of barrier. Career barriers were not related to indecision, whereas educational barriers were indirectly related to indecision through educational barriers coping efficacy. This result appears to be in line with results obtained by Lopez and Ann-Yi (2006). Although mediation tests were not performed, their results appeared more consistent with mediation hypothesis for educational barriers than for career barriers. This variation in results according to type of barrier can be explained by the way in which participants elaborated their future objectives. All types of barriers can be related to indecision. The greater the future barriers perceived by individuals, the harder their 
objectives are to define. Given that objectives are defined and updated in the course of education according to how well the individual copes with educational barriers, we can surmise that educational barriers coping efficacy is related to indecision. Career barriers coping efficacy was not related to indecision because this variable can play a role throughout people's professional lives, and not just during their education.

Results relative to social support seem to be in contradiction with results observed in previous studies. In our study, social support was not significantly related to indecision whereas Lent et al (2016) observed that the path between social support, decidedness and decisional anxiety was mediated by self-efficacy (including career decision self-efficacy and coping efficacy). This divergence can be explained by the measurement of different dimensions of self-efficacy. Career decision self-efficacy can mediate the path between social support and indecision, but it would not be the case for coping efficacy. In other words, social support would explain indecision via career decision self-efficacy, but not via barriers coping efficacy.

In a similar vein, we observed that social support was significantly correlated with educational barriers coping efficacy, but not with career barriers coping efficacy, contrary to results observed by Lopez and Ann-Yi (2006). In their study, the scale used to measure social support seem more specific, so the path between social support and coping efficacy may seem more obvious. Moreover, our different results according to type of barrier can be due to a different perception of career barriers and of educational barriers by our participants. Career barriers could be related to demographic variables, so, social support would not be useful to feel confident to cope with these barriers. Educational barriers could be related to other factors, like work organization, so, social support would be perceived as more useful.

Our results confirmed the paths between gender, social support and career barriers observed in previous studies (Cardoso \& Marques, 2008; Lindley, 2005; Luzzo \& McWhirter, 
2001; Raque-Bogdan et al., 2013). Women expected to encounter more career-related barriers and more social support than men.

Our results highlight the relevance of introducing coping efficacy and gender in a model adapted from the career self-management model applied to career exploration and decision-making behavior. To our knowledge, the specific role of coping efficacy has rarely been investigated, except by Byars-Winston and Fouad (2008). The results of their study suggested that the relationships between self-efficacy and other variables vary according to the dimension of self-efficacy. Investigations relative to the specificity of these paths need to be pursued.

\section{Limitations and Suggestions for Future Research}

The present study had several limitations. For a start, we used self-report data. This method may artificially increase correlations between variables, particularly when the data are cross-sectional, as they were in our study. Second, our model did not include career decision self-efficacy. Including this variable in a model would have made it possible to explore the paths between the career decision dimension of self-efficacy and the other variables in our model. According to Lent and Brown (2013), it can be useful to measure different types of self-efficacy according to the context. In our study, career decision self-efficacy might have been a more relevant variable than coping efficacy for mediating the path between social support and indecision, as shown by Restubog, Florentino and Garcia (2010). In a similar vein, Nota et al. (2007) found that the path between family support and indecision was mediated by career search efficacy. Third, it would have been more relevant to use a more specific measure of social support, as in previous studies (Lopez \& Ann-Yi, 2006; RaqueBogdan et al., 2013). Lopez and Ann-Yi (2006) used a measure of social support designed specifically for college students, while Raque-Bogdan et al. (2013) used a scale that focused on career-related parental support. This would have made it easier to compare our results with 
those of previous studies. Fourth, it would have been useful to test a model containing other variables included in the career self-management model applied to career exploration and decision-making behavior, such as decisional goals and decisional actions (Lent et al., 2003; Rogers, Creed, \& Glendon, 2008). The introduction of these variables would help to understand processes underlying the paths between dimensions of self-efficacy and indecision.

\section{Implications for Counseling}

These results highlight the need to develop interventions based on perceived educational barriers, social support and coping efficacy, particularly those aimed at women. Lent (2005) suggested several activities to cope with barriers and build support (e.g., identifying and anticipating possible barriers to choice implementation, analyzing the likelihood of encountering these barriers, preparing barrier coping strategies, and cultivating support for goals). Some of these support-focused activities have been included in existing programs (Fouad, Cotter, \& Kantamneni, 2009; Jackson, Kacanski, Rust, \& Beck, 2006). Jackson et al. (2006, p. 207) elaborated a workshop which aims to "expand (...) learning about accessible sources of support (...) for their educational and career goals and aspirations". They observed that participants endorsed a greater number of supports at the end of the workshop, and more of these supports were contextual. The course developed by Fouad et al. (2009, p. 341) aimed to help students with their career decision making, in particular by teaching "knowledge in how to effectively use a variety of resources to research occupations". This intervention had a nonsignificant effect on barrier perception. Some of the activities listed by Lent (2005) had previously featured in the Michigan JOBS reemployment program (Price \& Vinokur, 1995; Vinokur \& Schul, 1997). Price and Vinokur (1995) described several coping processes or instrumental skills implemented in this program (e.g., support mobilization and setback management). These processes included social support and barrier 
anticipation. This program has since been adapted to favor students' school-to-work transition (Koivisto, Vuori, \& Vinokur, 2010). One aim of this program was inoculation against setbacks through the identification of possible barriers, the generation of solutions, and training to overcome these barriers. A second aim was the identification of work-life goals, an ability that may be related to indecision. The beneficial effects of this program were shown in several studies, but its effect on coping efficacy and on perceived barriers was not investigated (Vinokur, Price, \& Schul, 1995; Vinokur \& Schul, 1997; Vinokur, Schul, Vuori, $\&$ Price, 2000). New studies are therefore needed to investigate the benefits of such programs.

\section{References}

Betz, N. E., \& Voyten, K. K. (1997). Efficacy and outcome expectations influence career exploration and decidedness. The Career Development Quarterly, 46(2), 179-189.

Byars-Winston, A. M., \& Fouad, N. A. (2008). Math and science social cognitive variables in college students: Contributions of contextual factors in predicting goals. Journal of Career Assessment, 16(4), 425-440. doi: 10.1177/1069072708318901

Cardoso, P., \& Marques, J. F. (2008). Perception of career barriers: The importance of gender and ethnic variables. International Journal for Educational and Vocational Guidance, 8(1), 49-61. doi: 10.1007/s10775-008-9135-y

Constantine, M. G., Wallace, B. C., \& Kindaichi, M. M. (2005). Examining Contextual Factors in the Career Decision Status of African American Adolescents. Journal of Career Assessment, 13(3), 307-319. doi: 10.1177/1069072705274960

Creed, P., Patton, W., \& Prideaux, L.-A. (2006). Causal Relationship Between Career Indecision and Career Decision-Making Self-Efficacy: A Longitudinal Cross-Lagged Analysis. Journal of Career Development, 33(1), 47-65. doi:

$10.1177 / 0894845306289535$ 
Feldman, D. C. (2003). The antecedents and consequences of early career indecision among young adults. Human Resource Management Review, 13(3), 499-531. doi: 10.1016/S1053-4822(03)00048-2

Fouad, N., Cotter, E. W., \& Kantamneni, N. (2009). The effectiveness of a career decisionmaking course. Journal of Career Assessment, 17(3), 338-347. doi: $10.1177 / 1069072708330678$

Guay, F., Senécal, C., Gauthier, L., \& Fernet, C. (2003). Predicting career indecision: A selfdetermination theory perspective. Journal of Counseling Psychology, 50(2), 165-177. doi: $10.1037 / 0022-0167.50 .2 .165$

Hartman, B. W., Fuqua, D. R., \& Hartman, P. T. (1983). The construct validity of the Career Decision Scale administered to high school students. Vocational Guidance Quarterly, $31(4), 250-258$.

Hartman, B. W., \& Hartman, P. T. (1982). The concurrent and predictive validity of the Career Decision Scale adapted for high school students. Journal of Vocational Behavior, 20(2), 244-252. doi: 10.1016/0001-8791(82)90012-4

Hu, L.-t., \& Bentler, P. M. (1999). Cutoff criteria for fit indexes in covariance structure analysis: Conventional criteria versus new alternatives. Structural Equation Modeling, 6(1), 1-55. doi: 10.1080/10705519909540118

Jackson, M. A., Kacanski, J. M., Rust, J. P., \& Beck, S. E. (2006). Constructively Challenging Diverse Inner-City Youth's Beliefs About Educational and Career Barriers and Supports. Journal of Career Development, 32(3), 203-218. doi: $10.1177 / 0894845305279161$

Koivisto, P., Vuori, J., \& Vinokur, A. D. (2010). Transition to work: Effects of preparedness and goal construction on employment and depressive symptoms. Journal of Research on Adolescence, 20(4), 869-892. doi: 10.1111/j.1532-7795.2010.00667.x 
Lent, R. W. (2005). A Social Cognitive View of Career Development and Counseling. In S. D. Brown \& R. W. Lent (Eds.), Career development and counseling: Putting theory and research to work. (pp. 101-127). Hoboken, NJ US: John Wiley \& Sons Inc.

Lent, R. W., \& Brown, S. D. (2013). Social cognitive model of career self-management: Toward a unifying view of adaptive career behavior across the life span. Journal of Counseling Psychology, 60(4), 557-568. doi: 10.1037/a0033446

Lent, R. W., Brown, S. D., \& Hackett, G. (1994). Toward a unifying social cognitive theory of career and academic interest, choice, and performance. Journal of Vocational Behavior, 45(1), 79-122. doi: 10.1006/jvbe.1994.1027

Lent, R. W., Brown, S. D., \& Hackett, G. (2000). Contextual supports and barriers to career choice: A social cognitive analysis. Journal of Counseling Psychology, 47(1), 36-49. doi: 10.1037/0022-0167.47.1.36

Lent, R. W., Brown, S. D., Schmidt, J., Brenner, B., Lyons, H., \& Treistman, D. (2003).

Relation of contextual supports and barriers to choice behavior in engineering majors: Test of alternative social cognitive models. Journal of Counseling Psychology, 50(4), 458-465. doi: 10.1037/0022-0167.50.4.458

Lent, R. W., Ezeofor, I., Morrison, M. A., Penn, L. T., \& Ireland, G. W. (2016). Applying the social cognitive model of career self-management to career exploration and decisionmaking. Journal of Vocational Behavior, 93, 47-57. doi: http://dx.doi.org/10.1016/j.jvb.2015.12.007

Lindley, L. D. (2005). Perceived Barriers to Career Development in the Context of Social Cognitive Career Theory. Journal of Career Assessment, 13(3), 271-287. doi: $10.1177 / 1069072705274953$ 
Lipshits-Braziler, Y., \& Tatar, M. (2012). Perceived career barriers and coping among youth in Israel: Ethnic and gender differences. Journal of Vocational Behavior, 80(2), 545554. doi: 10.1016/j.jvb.2011.08.010

Lopez, F. G., \& Ann-Yi, S. (2006). Predictors of Career Indecision in Three Racial/Ethnic Groups of College Women. Journal of Career Development, 33(1), 29-46. doi: $10.1177 / 0894845306287341$

Luzzo, D. A., \& McWhirter, E. H. (2001). Sex and ethnic differences in the perception of educational and career-related barriers and levels of coping efficacy. Journal of Counseling \& Development, 79(1), 61-67. doi: 10.1002/j.1556-6676.2001.tb01944.x

Nota, L., Ferrari, L., Solberg, V. S. H., \& Soresi, S. (2007). Career search self-efficacy, family support, and career indecision with Italian youth. Journal of Career Assessment, 15(2), 181-193. doi: 10.1177/1069072706298019

Osipow, S. H. (1987). Manual for the Career Decision Scale. Odessa, FL: Psychological Assessment Resources.

Osman, A., Lamis, D. A., Freedenthal, S., Gutierrez, P. M., \& McNaughton-Cassill, M. (2014). The Multidimensional Scale of Perceived Social Support: Analyses of internal reliability, measurement invariance, and correlates across gender. Journal of Personality Assessment, 96(1), 103-112. doi: 10.1080/00223891.2013.838170

Perrone, K. M., Civiletto, C. L., Webb, L. K., \& Fitch, J. C. (2004). Perceived Barriers to and Supports of the Attainment of Career and Family Goals Among Academically Talented Individuals. International Journal of Stress Management, 11(2), 114-131. doi: $10.1037 / 1072-5245.11 .2 .114$

Price, R. H., \& Vinokur, A. D. (1995). Supporting career transitions in a time of organizational downsizing: The Michigan JOBS program. In M. London (Ed.), 
Employees, careers and job creation: Developing growth-oriented human resource strategies and programs (pp. 191-209). San Francisco: Jossey-Bass.

Quimby, J. L., \& O'Brien, K. M. (2004). Predictors of Student and Career Decision-Making Self-Efficacy Among Nontraditional College Women. The Career Development Quarterly, 52(4), 323-339. doi: 10.1002/j.2161-0045.2004.tb00949.x

Raque-Bogdan, T. L., Klingaman, E. A., Martin, H. M., \& Lucas, M. S. (2013). Careerrelated parent support and career barriers: An investigation of contextual variables. The Career Development Quarterly, 61(4), 339-353. doi: 10.1002/j.21610045.2013.00060.x

Restubog, S. L. D., Florentino, A. R., \& Garcia, P. R. J. M. (2010). The mediating roles of career self-efficacy and career decidedness in the relationship between contextual support and persistence. Journal of Vocational Behavior, 77(2), 186-195. doi: 10.1016/j.jvb.2010.06.005

Rogers, M. E., Creed, P. A., \& Glendon, A. I. (2008). The role of personality in adolescent career planning and exploration: A social cognitive perspective. Journal of Vocational Behavior, 73(1), 132-142. doi: 10.1016/j.jvb.2008.02.002

Stead, G. B., \& Watson, M. B. (1993). How similar are the factor structures of the Career Decision Scale, the Career Decision Profile, and the Career Factors Inventory? Educational and Psychological Measurement, 53(1), 281-290. doi: $10.1177 / 0013164493053001031$

Tate, K. A., Fouad, N. A., Marks, L. R., Young, G., Guzman, E., \& Williams, E. G. (2015). Underrepresented first-generation, low-income college students' pursuit of a graduate education: Investigating the influence of self-efficacy, coping efficacy, and family influence. Journal of Career Assessment, 23(3), 427-441. doi:

$10.1177 / 1069072714547498$ 
Vinokur, A. D., Price, R. H., \& Schul, Y. (1995). Impact of the JOBS intervention on unemployed workers varying in risk for depression. American Journal of Community Psychology, 23(1), 39-74. doi: 10.1007/BF02506922

Vinokur, A. D., \& Schul, Y. (1997). Mastery and inoculation against setbacks as active ingredients in the JOBS intervention for the unemployed. Journal of Consulting and Clinical Psychology, 65(5), 867-877. doi: 10.1037/0022-006X.65.5.867

Vinokur, A. D., Schul, Y., Vuori, J., \& Price, R. H. (2000). Two years after a job loss: Longterm impact of the JOBS program on reemployment and mental health. Journal of Occupational Health Psychology, 5(1), 32-47. doi: 10.1037/1076-8998.5.1.32

Watts, L. L., Frame, M. C., Moffett, R. G., Van Hein, J. L., \& Hein, M. (2015). The relationship between gender, perceived career barriers, and occupational aspirations. Journal of Applied Social Psychology, 45(1), 10-22. doi: 10.1111/jasp.12271

Zimet, G. D., Dahlem, N. W., Zimet, S. G., \& Farley, G. K. (1988). The Multidimensional Scale of Perceived Social Support. Journal of Personality Assessment, 52(1), 30-41. doi: 10.1207/s15327752jpa5201_2 
Table 1

Descriptive Statistics and Correlation Matrix

\begin{tabular}{|c|c|c|c|c|c|c|c|c|}
\hline & $M$ & $S D$ & 1 & 2 & 3 & 4 & 5 & 6 \\
\hline 1. Gender $^{\mathrm{a}}$ & & & & & & & & \\
\hline 2. Social support & 5.67 & 1.14 & $.31 * * *$ & & & & & \\
\hline 3. Career barriers & 2.61 & .66 & $.36 * * *$ & .07 & & & & \\
\hline 4. Educational barriers & 2.89 & .60 & .08 & $-.24 * *$ & $.53^{* * *}$ & & & \\
\hline 5. Career barriers coping efficacy & 3.66 & .58 & $-.30^{* * *}$ & .05 & $-.46^{* * *}$ & $-.30^{* * *}$ & & \\
\hline 6. Educational barriers coping efficacy & 3.39 & .64 & -.11 & $.24 * *$ & $-.30^{* * *}$ & $-.57 * * *$ & $.64 * * *$ & \\
\hline 7. Vocational indecision & 33.94 & 10.00 & .01 & $-.20 *$ & $.22 * *$ & $.36^{* * *}$ & $-.17^{*}$ & $-.37 * * *$ \\
\hline
\end{tabular}


Figure 1. Standardized path coefficients between gender, barriers, coping efficacy, social support and vocational indecision.

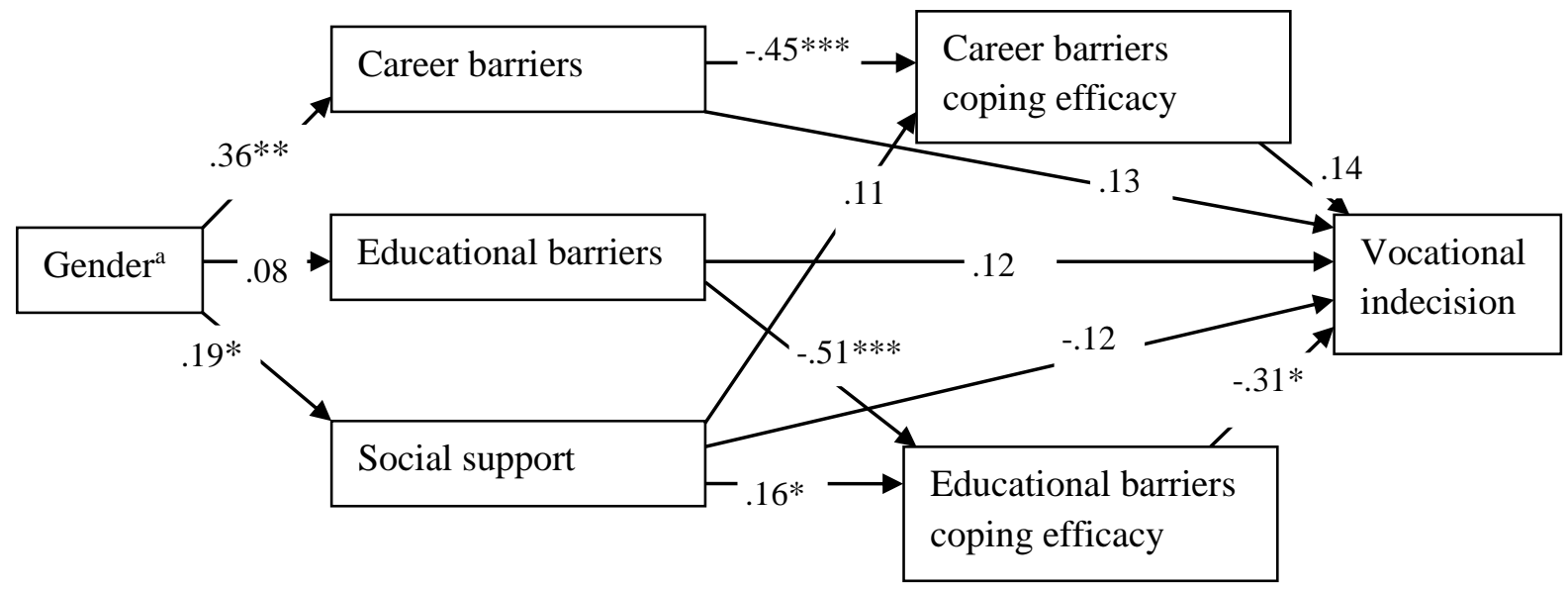

$* p<.05 . * * p<.01 * * * p<.001$.

${ }^{\mathrm{a}} 1=$ male, $2=$ female. 